\title{
The Role of the B7 Costimulatory Pathway in Experimental Cold Ischemia/Reperfusion Injury
}

\author{
Moriatsu Takada, ${ }^{\star}$ Anil Chandraker, ${ }^{\ddagger}$ Kari C. Nadeau, ${ }^{\S}$ Mohamed H. Sayegh, ${ }^{\ddagger}$ and Nicholas L. Tilney \\ *Surgical Research Laboratory and Department of Surgery, and ${ }^{\ddagger}$ Renal Division, Department of Medicine, Brigham and Women’s \\ Hospital; and ${ }^{\S}$ Department of Pediatrics, Children’s Hospital Medical Center, Harvard Medical School, Boston, Massachusetts 02115
}

\begin{abstract}
Ischemia/reperfusion injury associated with organ retrieval and storage influences the development of chronic graft dysfunction, the major clinical problem in solid organ transplantation. The potential role of mononuclear cells ( $T$ cells and monocyte/macrophages) in this type of injury is unknown. Inbred male Lewis rats were uninephrectomized and the left kidney perfused in situ with $10 \mathrm{ml}$ of iced University of Wisconsin solution. Immunohistological studies showed mononuclear cell infiltration of the ischemic organs associated with the upregulation of MHC class II antigen expression. Reverse transcriptase-PCR indicated that $T$ cell associated cytokines and monocyte/macrophage activation markers/products are upregulated early after the ischemic insult. B7 expression occurred within $24 \mathrm{~h}$ and peaked at $3 \mathrm{~d}$. Plasma creatinine levels rose transiently with complete recovery of renal function by $5 \mathrm{~d}$. Animals began to develop progressive proteinuria after $8-12 \mathrm{wk}$, indicative of the long-term functional consequences of early ischemia/reperfusion injury. Blockade of T cell CD28-B7 costimulation with CTLA4Ig resulted in significant inhibition of $T$ cell and macrophage infiltration and activation in situ. Treated animals did not exhibit transient renal dysfunction, nor developed proteinuria over time. This is the first demonstration that blocking $\mathrm{T}$ cell costimulatory activation in the absence of alloantigen can prevent the early and late consequences of ischemia/reperfusion injury. (J. Clin. Invest. 1997. 100: 1199-1203.) Key words: rat $\bullet$ kidney $\cdot \mathrm{CD} 28-\mathrm{B} 7 \cdot \mathrm{T}$ cell
\end{abstract}

\section{Introduction}

Ischemia/reperfusion injury associated with retrieval, storage, and transplantation of solid organs from cadavers adversely affects early graft function and may be a major factor limiting long-term graft survival $(1,2)$. In the case of renal allografts, this may be due, in part, to difficulties in recognizing and treating acute rejection in patients with delayed graft function requiring dialysis (acute rejection being the major clinical risk factor for development of chronic rejection) (3). It has also been noted in experimental models that the ischemic insult

M.H. Sayegh and N.L. Tilney are co-senior authors.

Address correspondence to Dr. Mohamed H. Sayegh, Brigham and Women's Hospital, 75 Francis St., Boston, MA 02115. Phone: 617-7325259; FAX: 617-732-5254; E-mail: sayegh@bustoff.bwh.harvard.edu

Received for publication 13 March 1997 and accepted in revised form 28 May 1997.

J. Clin. Invest.

(C) The American Society for Clinical Investigation, Inc. 0021-9738/97/09/1199/05 \$2.00

Volume 100, Number 5, September 1997, 1199-1203

http://www.jci.org may increase the immunogenicity of the organ by upregulating MHC class II antigens (4).

Although T lymphocytes and macrophages have been welldemonstrated to infiltrate kidney tissue within a few days of ischemia/reperfusion injury (5), the effects and function of these cell populations in the injury process remain unknown.

Two distinct signals are required for full $\mathrm{T}$ cell activation (6). The first signal is delivered by the T cell receptor (TCR) after engagement with the MHC-peptide complex expressed on the surface of antigen presenting cells (APCs). The second costimulatory signal is provided by cell surface receptors after binding to their ligands, particularly important is CD28 on $\mathrm{T}$ cells binding to its ligands, CD80(B7-1), and CD86(B7-2) on APCs. Signaling through the TCR alone, which leads to a state of specific T cell anergy, may be produced by blocking the second signal (7). Binding of CD28 by CD80 and/or CD86 may be blocked by CTLA4Ig, ${ }^{1}$ a recombinant fusion protein that has the extracellular domain of human CTLA4 (a homologue of CD28) fused to an IgG1 heavy chain (8). CTLA4Ig inhibits T cell activation in vitro and in vivo (9), prevents acute (10-13) and chronic $(14,15)$ allograft rejection, and induces tolerance in some experimental transplantation models $(12,16)$. Here we report on the role of CD28-B7 T cell costimulatory activation in a rat model of experimental renal ischemia/reperfusion injury.

\section{Methods}

Experimental design and operative technique. Inbred male Lewis (LEW) rats of 250-300 g (Harlan Sprague Dawley Inc., Indianapolis, IN) were used. A cold ischemia/reperfusion injury model of renal injury has been described recently (5). Briefly, the right kidney of normal LEW rats was removed and the left kidney was isolated. The aorta was occluded proximal and distal to the left renal artery, and the left renal vein clamped with a vascular clip near its junction with the inferior vena cava. The aorta was catheterized with a silicone tube (Silicone Medical Grade Tubing, 0.02 inch inside diameter, 0.037 inch outside diameter; Baxter Scientific Products, Edison, NJ) and a drainage vent made in the renal vein proximal to the vascular clip. The isolated kidney was then perfused slowly (2-3 min) with $10 \mathrm{ml}$ of iced perfusion solution consisting of $83.33 \%$ by volume of University of Wisconsin solution $\left(\mathrm{K}_{2} \mathrm{HPO}_{4}, 3.38 \mathrm{mg} / \mathrm{ml} ; \mathrm{KH}_{2} \mathrm{PO}_{4}, 8.16 \mathrm{mg} / \mathrm{ml} ; \mathrm{KCL}\right.$, $\left.1.23 \mathrm{mg} / \mathrm{ml} ; \mathrm{NaHCO}_{3}, 0.45 \mathrm{mg} / \mathrm{ml}\right), 8.33 \%$ by volume of Albumin U.S.P. (Albutein; Alpha Therapeutic Corporation, Los Angeles, CA) and $8.33 \%$ by volume of $50 \%$ Dextrose Injection (Abbott Laboratories, North Chicago, IL). The vascular pedicle was then clamped at the level of the hilum for a total ischemic time of $45 \mathrm{~min}$. During that time, the involved vessels were repaired with 7-0 monofilament suture (Proline; Ethicon Inc., Somerville, NJ) and the other clamps released.

1. Abbreviations used in this paper: CTLA4Ig, CTLA4 fused to an IgG1 heavy chain; RANTES, regulated upon activation, normal $\mathrm{T}$ cell expressed and secreted; RT-PCR, reverse transcriptase-PCR. 
Treatment protocols. CTLA4Ig and control human fusion protein L6 were a generous gift of Dr. Peter Linsley (Bristol-Myers Squibb, Seattle, WA). The experimental group was given CTLA4Ig for one week $(0.5 \mathrm{mg}$ i.v. on the day of operation and $0.1 \mathrm{mg}$ daily for $7 \mathrm{~d})$. The controls received a similar protocol of control fusion protein. Uninjured kidneys in untreated uninephrectomized rats were used as further controls.

Functional measurements. Blood samples $(0.5 \mathrm{ml})$ for creatinine determination were obtained from the tail vein at $0,1,2,3$, and $5 \mathrm{~d}$ after reperfusion. Creatinine was measured by a modified Jaffe's reaction on a Hitachi 911 autoanalyzer (Hitachi, Indianapolis, IN). Urine samples (24 h) were collected at 4, 8, 16, and 24 wk after reperfusion. Protein excretion was determined by precipitation with $3 \%$ sulfosalicylic acid (Fisher Scientific Co., Fairlawn, NJ). Turbidity was assessed by absorbance at a wavelength of $595 \mathrm{~nm}$ using Beckman DU-64 spectrophotometer (17).

Immunohistology. Representative portions of the kidneys were snap-frozen in liquid nitrogen at 1, 3, 5, and $7 \mathrm{~d}$ after operation. Sections $(4 \mu \mathrm{m})$ were fixed in acetone for $10 \mathrm{~min}$, air-dried, and stained individually with mouse anti-rat antibodies. The specimens were stained with ED-1 for monocytes/macrophages W3/25 for CD $4^{+}$cells, OX-8 for $\mathrm{CD}^{+}$cells and OX-3 for MHC class II (Bioproducts for Science Inc., Indianapolis, IN). The sections were then interacted with rabbit anti-mouse IgG by the alkaline phosphatase, antialkaline phosphatase method and counterstained with hematoxylin (18). Stained cells were then counted on an ocular grid and marker positive cells expressed as mean \pm SD of cells per field of view (cells per FV, $400 \times,>30$ fields counted per specimen).

Reverse transcriptase-PCR (RT-PCR). The expression of mRNA was examined by competitive RT-PCR (19). Total RNA of kidney specimens was extracted by the guanidine isothiocyanate method (20). Total RNA $(2.5 \mu \mathrm{g})$ was used for first strand cDNA synthesis employing $1.2 \mu \mathrm{g}$ of oligo $\mathrm{dT}_{12-18}$ and the superscript reverse transcriptase method according to supplier-recommended conditions (GIBCO BRL, Gaithersburg, MD). The specific primers (CD80, IL-2, IL-2R, IFN $\gamma$, IL-6, TGF $\beta$, TNF $\alpha$, regulated upon activation, normal $\mathrm{T}$ cell expressed and secreted (RANTES), MCP-1, NOSi, and $\beta$-actin) were used as described $(21,22)$. 2-fold to 10-fold serial dilutions of known quantities of PCR MIMICS were added to the PCR reaction containing constant amounts of sample target cDNA. PCR products $(5 \mu \mathrm{l})$ were run on $1.5 \%$ agarose gel and stained with an ethidium bromide, then gene-specific bands were visualized with ultraviolet light. The quantities of MIMICS and target cDNA were compared using a PC SCANJET with analysis by Adobe Photoshop software (Adobe Inc., Mountain View, CA). Tissues were tested for each cytokine mRNA transcript as well as for the control $\beta$-actin mRNA transcript. Transcript levels for each PCR product were determined by scanner analysis of photographs of the DNA-stained agarose gels evaluated by the band intensity in computer image analysis. The results are expressed as arithmetric means ( \pm SEM). Statistical comparisons between groups were performed by Student's $t$ test. The difference was considered significant when $P<0.05$.

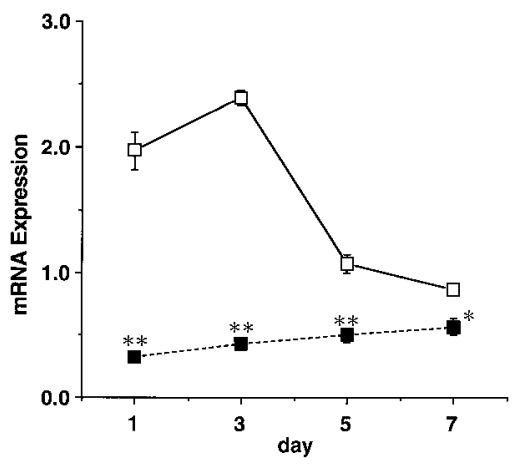

Figure 1. Effect of CTLA4Ig in B7 expres-

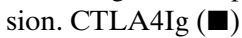
downregulates B7 expression which is highly expressed by day 3 in controls $(\square) . * P<0.05$, ** $P<0.01$ compared to control Ig treatment.
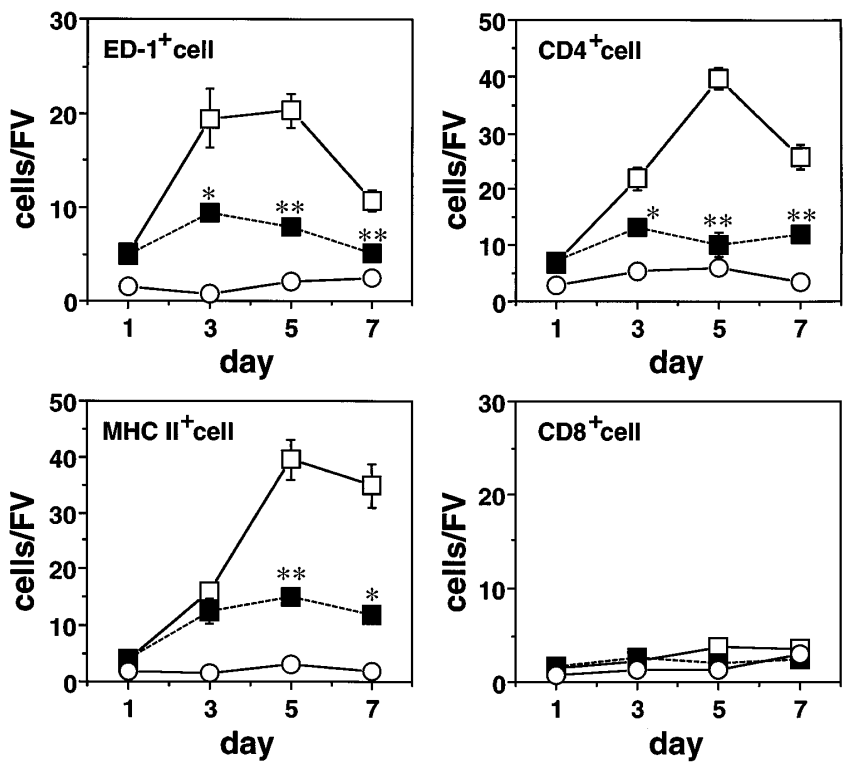

Figure 2. Kinetics of cell infiltration into ischemic kidney. ED-1 ${ }^{+}$ macrophages peaked between days 3 and $5, \mathrm{CD}^{+}$and $\mathrm{CD} 8^{+} \mathrm{T}$ lymphocytes at day 5, MHC class II cells peaked on days 5-7 in cold ischemia with control Ig ( $\square$ ). Cell infiltration patterns were suppressed significantly by CTLA4Ig (ם). Uninephrectomized controls $(\bigcirc)$ showed minimal cell infiltration. $* P<0.05$, $* * P<0.01$ compared to control Ig treatment.

\section{Results}

Expression of the costimulatory molecule B7 during ishemial reperfusion injury. First, we examined the expression of B7 costimulatory molecules in organs subjected to ischemia/reperfusion injury by RT-PCR. Expression of the costimulatory molecule B7 was upregulated in ischemic kidneys within the first few hours after injury and peaked at 24-72 h. Administration of CTLA4Ig almost completely inhibited upregulation of B7 expression in the ischemic organ as compared to control Ig (Fig. 1).

CTLA4Ig inhibits mononuclear cell infiltration and activation in situ. Mononuclear cell population and subpopulation infiltrating the renal parenchyma, as determined by immunohistology using specific monoclonal antibodies, were studied in control uninephrectomized rats and in Ig- and CTLA4Igtreated animals 3,5, and $7 \mathrm{~d}$ after the ischemia/reperfusion injury (Fig. 2). Infiltration by ED $-1^{+}$macrophages, CD $4^{+} \mathrm{T}$ cells, and $\mathrm{MHC}$ class $\mathrm{II}^{+}$cells was inhibited significantly at all time points by CTLA4Ig as compared to control groups.

Next, we studied the effect of CTLA4Ig treatment on mRNA expression of cytokines and growth factors in situ. Competitive RT-PCR analysis of kidneys that underwent ischemia/reperfusion injury showed significant expression of the $\mathrm{T}$ cell activation markers (Fig. $3 A$ ). Time course expression recently described IL-2, IL-2R, and IFN $\gamma$ (5). RANTES, a macrophage chemoattractant derived from $\mathrm{T}$ cells and other cell populations, remained upregulated by $2 \mathrm{wk}$. The macrophage associated products, TNF $\alpha$ and IL-6, were significantly expressed by day 3 (Fig. $3 \mathrm{~B}$ ). NOSi increased gradually by $2 \mathrm{wk}$. Transcript levels of the chemoattractant MCP-1 were highly expressed by day 7, and expression of the fibrogenic growth factor TGF $\beta$ was increased significantly by day 5 (Fig. $3 C$ ). 
A
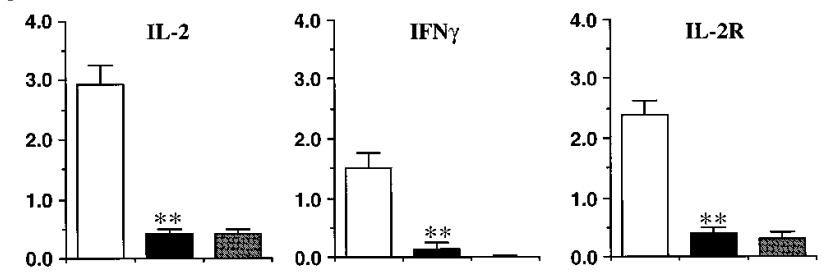

B
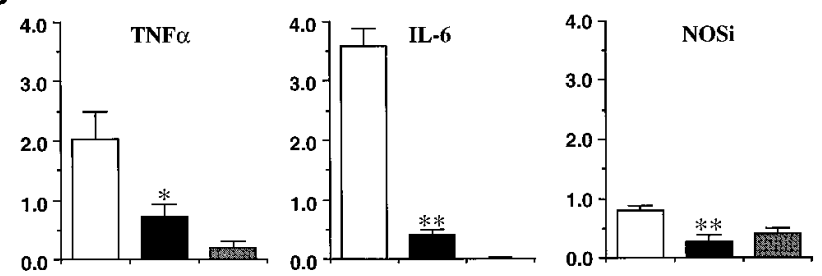

C
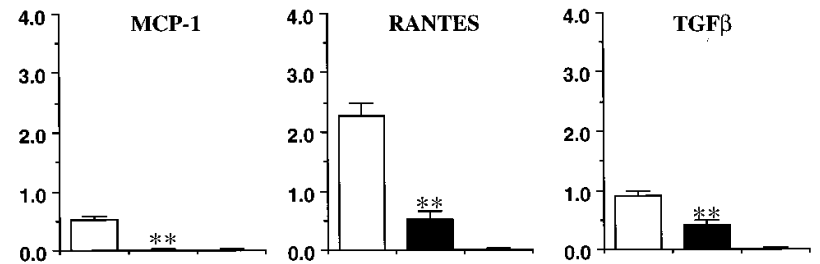

Figure 3. Comparison of gene expression in cold ischemia kidney. $(A)$ Th1 associated cytokines, $(B) \mathrm{M} \phi$ associated cytokines, and $(C)$ chemoattractant and growth factors. The peak expression of each cytokine/cytokine receptor (day 3: IL-2, IL-2R, TNF $\alpha$, IL-6; day 5: TGF $\beta$; day 7: IFN $\gamma$, MCP-1; day 14: RANTES, NOSi) was assessed to evaluate the suppressive effect of CTLA4Ig (black bars) compared with control Ig (white bars). Uninephrectomized control (gray bars) showed little expression. ${ }^{*} P<0.05,{ }^{* *} P<0.01$ compared to control Ig treatment.

Administration of CTLA4Ig resulted in significant and almost complete inhibition of expression of all mononuclear cell activation markers and products tested as compared to control Ig (Fig. 3).

CTLA4Ig prevents ischemia/reperfusion induced acute renal dysfunction. We studied the effect of inhibiting T cell costimulatory activation on renal function after ischemia/reperfusion injury. Levels of serum creatinine were monitored for $5 \mathrm{~d}$ after cold ischemia/reperfusion injury in control Ig- and CTLA4Ig-treated animals, and in uninephrectomized controls (Fig. 1). Rats whose kidneys had experienced cold ischemia showed transient dysfunction (peak serum creatinine $=2.6 \pm$ $0.4 \mathrm{mg} / \mathrm{dl}$ on day 2) with complete recovery by day 5 , as compared with uninephrectomized control animals. Treatment with CTLA4Ig completely protected against this transient renal dysfunction; no increase in serum creatinine was noted, as compared to control Ig-treated animals.

CTLA4Ig prevents late renal dysfunction associated with ischemia/reperfusion injury. It has been suggested that early injury resulting from ischemia/reperfusion may lead to development of late progressive organ dysfunction, although definitive proof is lacking. We monitored protein excretion, a sensitive measure of renal dysfunction that can be detected even before significant decrease in glomerular filtration rate or rise

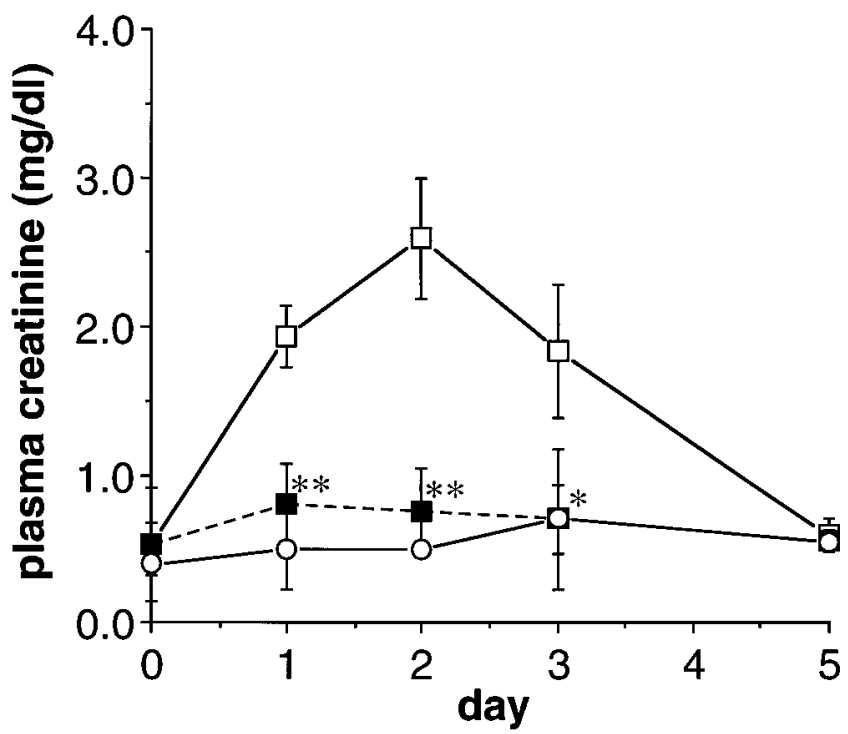

Figure 4. Plasma creatinine levels of animals with cold ischemic kidneys. Transient renal dysfunction was identified after cold ischemia alone and after treatment with control Ig $(\square)$. The CTLA4Ig ( $\square)$ treated group showed no renal dysfunction, compared to the uninephrectomized control group $(\bigcirc)$. ${ }^{*} P<0.05$, ${ }^{*} P<<0.01$ compared to control Ig treatment.

in serum creatinine can be measured, for up to $24 \mathrm{wk}$ in animals which underwent ischemia/reperfusion injury. These animals developed progressive proteinuria $(24 \mathrm{~h}$ protein excretion $=25.2 \pm 3.8 \mathrm{mg} / \mathrm{dl}$ at $24 \mathrm{wk})$ that was not observed in uninephrectomized controls. Interestingly, animals treated with CTLA4Ig did not develop progressive proteinuria through the whole follow-up period $(24 \mathrm{~h}$ protein excretion $=$ $9.1 \pm 0.8 \mathrm{mg} / \mathrm{dl}$ ) (Fig. 5), indicating that inhibiting B7 costimulatory activation early during ischemia/reperfusion injury prevents the late sequellae of chronic organ dysfunction.

\section{Discussion}

In this study we have examined the role of the CD28-B7 costimulatory pathway in the pathogenesis of experimental renal ischemia/reperfusion injury. Our results clearly demonstrate that blocking CD28-B7 T cell costimulation by the fusion protein CTLA4Ig significantly and almost completely prevents

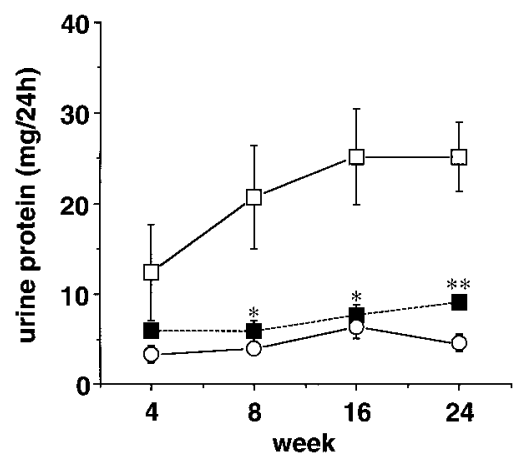

Figure 5. Urine protein for $24 \mathrm{wk}$ after cold ischemia/reperfusion. CTLA4 $\operatorname{Ig}(\mathbf{\square})$ significantly revealed suppressive effect for the development of chronic renal failure, compared with control Ig ( $\square$ ) to the same level as the uninephrectomized control group $(\mathrm{O})$. $* P<0.05, * * P<0.01$ compared to control Ig treatment. 
early transient, as well as late, organ dysfunction. Our observations underscore the important role of the B7 costimulatory pathway in ischemia/reperfusion injury. The observations of early expression of B7 costimulatory molecules in ischemic organs are particularly interesting since this is the first demonstration of upregulation of costimulatory molecule expression in a nonimmune, inflammatory response in the absence of alloantigen. Our RT-PCR data do not indicate whether B7 is expressed on infiltrating mononuclear cells, on endothelial cells, or both. The early upregulation of expression within the first $24 \mathrm{~h}$ before any significant infiltration may suggest that the B7 expression is predominantly on endothelial cells, although RT-PCR may be sensitive enough to detect B7 expression by a small number of early infiltrating mononuclear cells even before they can be visualized by immunohistology. Studies to dissect the temporal, as well as local, expression of CD80 versus CD86 in our model are important to understand better the role of these molecules in ischemia/reperfusion injury. Studies by Kelly et al. showed that blocking intercellular adhesion molecule-1 (ICAM-1) protects the kidney from ischemic injury (23). Turcovski-Corrales et al. (24) indicated that CD28-B7 interactions promote $\mathrm{T}$ cell adhesion mediated by interaction of ICAM-1:LFA-1 and LFA-3:CD2. This CD28-B7 induced adhesion required specific $\mathrm{T}$ cell signaling via protein kinase $\mathrm{C}$. Taken together with results of these two studies, our data suggest that blocking B7 costimulatory molecules may result in inhibition of adhesion of mononuclear cells to renal endothelium resulting in decreased infiltration into the organ and prevention of subsequent injury.

Clinical evidence from cadaver transplantation indicates the important contribution of ischemic injury to early graft dysfunction and acute rejection as well as to long term graft outcome $(1,2)$. In addition, mounting evidence from experimental animals indicates that chronic allograft dysfunction is mediated by both alloantigen-dependent as well as alloantigen-independent mechanisms, with graft ischemia/reperfusion being an important alloantigen-independent factor (25). The mechanisms of how graft ischemia contributes to early, as well as late, graft dysfunction remain unclear, although it has been suggested the ischemic injury increases the immunogenicity of the graft (4), mainly because of upregulation of class II MHC antigens. As MHC class II alone is insufficient to cause full $\mathrm{T}$ cell activation (26), additional upregulation of the costimulatory molecules B7 is essential in regulating this increased immunogenicity. Our data also show that ischemic organs are infiltrated early by activated $\mathrm{CD}^{+} \mathrm{T}$ cells and monocytes/ macrophages which secrete cytokines, chemoattractants, and growth factors. Cytokines, such as IFN $\gamma$ and $\mathrm{TNF} \alpha$, are potent inducers of MHC class II antigen expression (27). RANTES may facilitate $\mathrm{T}$ cell and macrophage accumulation by direct chemotactic effects or by regulating the expression of macrophage products (28). The macrophage derived cytokine IL-6 and NOSi are reported to relate to development of chronic graft dysfunction $(29,30)$, while TGF $\beta$ is considered to have a role in late fibrosis of the kidney $(31,32)$. These molecules may be relevant to the development of late graft dysfunction manifested by progressive proteinuria. Blocking B7 by CTLA4Ig results in profound inhibition of mononuclear cell infiltration and activation in situ, thus attenuating the early and late functional effects of ischemia/reperfusion injury. Our observations have relevant clinical applicability since strategies targeted at costimulatory blockade may prevent early and long-term con- sequences of early ischemia/reperfusion injury seen in cadaveric organ transplantation.

\section{Acknowledgments}

This work was supported by U.S. Public Health Service grants 9 R01 DK 46190-23 and P01 AI 40152-01. M.H. Sayegh is recipient of the National Kidney Foundation Clinician Scientist Award.

\section{References}

1. Land, W., and K. Messmer. 1996. The impact of ischemia/reperfusion injury on specific and nonspecific, early and late chronic events after organ transplantation. Transplant. Rev. 20:108-127.

2. Naimark, D.M.J., and E. Cole. 1994. Determinants of long-term renal allograft survival. Transplant. Rev. 3:93-113.

3. Carpenter, C.B. 1995. Long-term failure of renal transplants: adding insult to injury. Kidney Int. 50:s40-s44.

4. Goes, N., J. Urmson, V. Ramassar, and P.F. Halloran. 1995. Ischemic acute tubular necrosis induces an extensive local cytokine response. Transplantation (Baltimore). 59:565-572.

5. Takada, M., K.C. Nadeau, G.D. Shaw, K.A. Marquette, and N.L. Tilney. 1997. The cytokine-adhesion molecule cascade in ischemia/reperfusion injury of the kidney: inhibition by a soluble P-selectin ligand. J. Clin. Invest. 99:1-9.

6. Schwartz, R.H. 1992. Costimulation of T lymphocytes: the role of CD28, CTLA-4, and B7/BB1 in interleukin-2 production and immunotherapy. Cell. 71 : 1065-1068.

7. Tan, P., C. Anasetti, J.A. Hansen, J. Melrose, M. Brunvand, J. Bradshaw, J.A. Ledbetter, and P.S. Linsley. 1993. Induction of alloantigen-specific hyporesponsiveness in human T lymphocytes by blocking interaction of CD28 with its natural ligand B7/BB1. J. Exp. Med. 177:165-173.

8. Linsley, P.S., A. Clarke, and J.A. Ledbetter. 1990. T-cell antigen CD28 mediates adhesion with B cells by interacting with activation antigen B7/BB-1. Proc. Natl. Acad. Sci. USA. 87:5031-5035.

9. Linsley, P.S., P.M. Wallace, J. Johnson, M.G. Gibson, J.L. Greene, J.A Ledbetter, C. Singh, and M.A. Tepper. 1992. Immunosuppression in vivo by a soluble form of the CTLA-4 T cell activation molecule. Science (Wash. DC). 257:792-795.

10. Lenschow, D.J., Y. Zeng, J.R. Thistlethwaire, A. Montag, W. Brady, M.G. Gibson, P.S. Linsley, and J.A. Bluestone. 1992. Long-term survival of xenogenic pancreatic islet grafts induced by CTLA4Ig. Science (Wash. DC). 257: 789-792.

11. Turka, L.A., P.S. Linsley, H. Lin, W. Brady, J.M. Leiden, R.-Q. Wei, M.L. Gibson, X.-G. Zheng, S. Myrdal, D. Gordon, et al. 1992. T-cell activation by the CD28 ligand B7 is required for cardiac allograft rejection in vivo. Proc. Natl. Acad. Sci. USA. 89:11102-11105.

12. Sayegh, M.H., E. Akalin, W.W. Hancock, M.E. Russel, C.B. Carpenter, P.S. Linsley, and L.A. Turka. 1995. CD28-B7 blockade after alloantigenic challenge in vivo inhibits Th1 cytokines but spares Th2. J. Exp. Med. 181:1869-1874.

13. Perico, N., O. Imberti, M. Bontempelli, and G. Remuzzi. 1995. Toward novel antirejection strategies: in vivo immunosuppressive properties of CTLA4Ig. Kidney Int. 47:241-246.

14. Russell, M.E., W.W. Hancock, E. Akalin, A.F. Wallace, T. Glysing Jensen, T.A. Willett, and M.H. Sayegh. 1996. Chronic cardiac rejection in the LEW to F344 rat model. Blockade of CD28-B7 costimulation by CTLA4Ig modulates $\mathrm{T}$ cell and macrophage activation and attenuates arteriosclerosis. $J$. Clin. Invest. 97:833-838.

15. Azuma, H., A. Chandraker, K.C. Nadeau, W.W. Hancock, C.B. Carpenter, N.L. Tilney, and M.H. Sayegh. 1996. Blockade of T-cell costimulation prevents development of experimental chronic renal allograft rejection. Proc. Natl. Acad. Sci. USA. 93:12439-12444.

16. Pearson, T.C., D.Z. Alexander, K.J. Winn, P.S. Linsley, R.P. Lowry, and C.P. Larsen. 1994. Transplantation tolerance induced by CTLA4-Ig. Transplantation (Baltimore). 57:1701-1706.

17. Davidson, L., and J.B. Henry. 1969. Clinical Diagnosis by Laboratory Methods. 14th ed. W.B. Saunders Company, Philadelphia, PA. 48 pp.

18. Hancock, W.W., R.H. Lord, A.J. Colby, T. Diamantstein, F.R. Rickles, C. Dijktra, N. Hogg, and N.L. Tilney. 1987. Identification of IL 2R+ T cells and macrophages within rejecting rat cardiac allografts, and comparison of the effects of treatment with anti-IL $2 \mathrm{R}$ monoclonal antibody or cyclosporin. J. Immunol. 138:164-170.

19. Platzer, C., S. Ode-Hakim, P. Reike, W.-D. Döcke, R. Ewert, and H.-D. Volk. 1994. Quantitative PCR analysis of cytokine transcription patterns in peripheral mononuclear cells after anti-CD3 rejection therapy using two novel multispecific competitor fragments. Transplantation (Baltimore). 58:264-268.

20. Chomczynski, P., and N. Sacchi. 1987. Single-step method of RNA isolation by acid guanitidium thiocyanate-phenol-chloroform extraction. Anal. Biochem. 162:156-161.

21. Chandraker, A., M.E. Russell, T. Glysing-Jensen, T.A. Willett, and 
M.H. Sayegh. 1997. T cell costimulatory blockade in experimental chronic cardiac allograft rejection: effects of cyclosporine and donor antigen. Transplantation (Baltimore). 63:1053-1058.

22. Nadeau, K.C., H. Azuma, and N.L. Tilney. 1995. Cytokine expression in chronic rejection: role for MCP-1 and RANTES. Proc. Natl. Acad. Sci. USA. 92:8729-8733.

23. Kelly, K.J., W.W. Williams, Jr., R.B. Colvin, and J.V. Bonventre. 1994. Antibody to intracellular adhesion molecule 1 protects the kidney against ischemic injury. Proc. Natl. Acad. Sci. USA. 91:812-816.

24. Turcovski-Corrales, S.M., R.G. Fenton, G. Peltz, and D.D. Taub. 1995. CD28:B7 interactions promote T cell adhesion. Eur. J. Immunol. 25:3087-3093.

25. Tullius, S.G., and N.L. Tilney. 1995. Both alloantigens-dependent and -independent factors influence chronic allograft rejection. Transplantation (Baltimore). 59:313-318.

26. Sayegh, M.H., and L.A. Turka. 1995. T cell costimulatory pathways: promising novel targets for immunosuppression and tolerance induction. J. Am. Soc. Nephrol. 6:1143-1150.

27. Halloran, P.F. J. Urmson, P.H. Van der Meide, and P. Autenried 1992 Regulation of MHC expression in vivo. II. IFN-alpha/beta inducers and recombinant IFN-alpha modulate MHC antigen expression in mouse tissues. J. Im- munol. 142:4241-4247.

28. Schall, T.J., K. Bacon, K.J. Toy, and D.V. Goeddel. 1990. Selective attraction of monocytes and $\mathrm{T}$ lymphocytes of the memory phenotype by cytokine RANTES. Nature (Lond.). 347:669-671.

29. Russell, M.E., A.F. Wallace, W.W. Hancock, M.H. Sayegh, D.H. Adams, N.E.S. Sibinga, L.R. Wyner, and M.J. Karnovsky. 1995. Upregulation of cytokines associated with macrophage activation in the Lewis-F344 rat transplantation model of chronic cardiac rejection. Transplantation (Baltimore). 59: 572-578.

30. Russell, M.E., A.F. Wallace, L.R. Wyner, J.B. Newell, and M.J. Karnovsky. 1994. Upregulation and modulation of inducible nitric oxide synthase in rat cardiac allografts with chronic rejection and transplant arteriosclerosis. Circulation. 92:457-464.

31. Yamamoto, T., N.A. Noble, D.E. Miller, and W.A. Border. 1994. Sustained expression of TGF-beta 1 underlies development of progressive kidney fibrosis. Kidney Int. 45:916-927.

32. Sharma, V.K., R.M. Bologa, G.P. Xu, B. Li, J. Mouradian, J. Wang, D. Serur, V. Rao, and M. Suthanthiran. 1996. Intragraft TGF-beta 1 mRNA: a correlate of interstitial fibrosis and chronic allograft nephropathy. Kidney Int. 49: 1297-1303. 